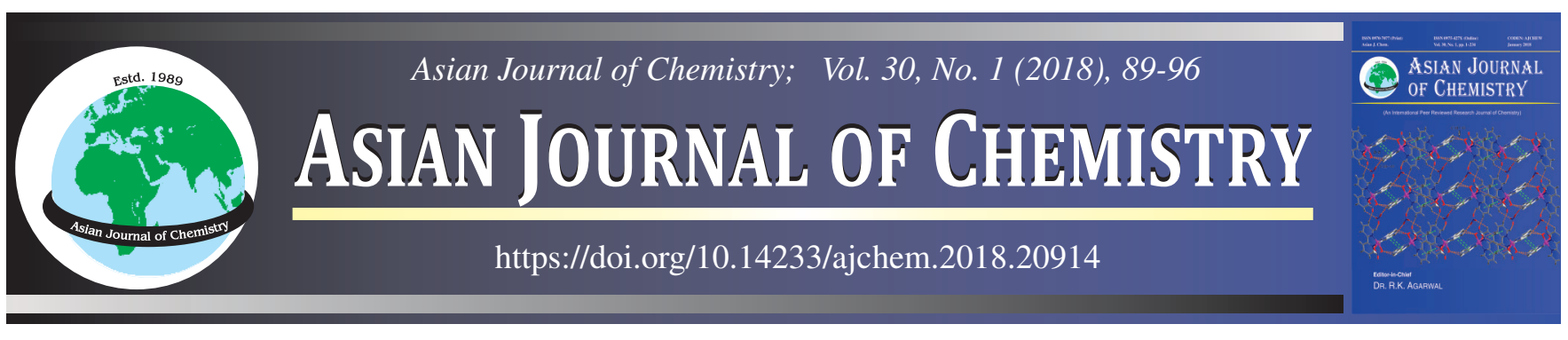

\title{
Graphene Oxide Supported Ruthenium, Silver and Ruthenium-Silver Nanoparticles as Catalyst with Antibacterial Activity
}

Perumal Andal ${ }^{*}$ and Roopakala

Department of Chemistry, School of Basic sciences, Vels University, Pallavaram, Chennai-600 117, India

*Corresponding author: E-mail: andalprithu.sbs@velsuniv.ac.in

\begin{abstract}
In this study, two different types of graphene oxide supported nanoparticles e.g., ruthenium, silver and a bimetallic Ru-Ag nanoparticles were synthesized. The size and shape of the products were characterized by various techniques viz., scanning electron microscopy (SEM), high resolution transmission electron microscopy (HRTEM) field emission scanning electron microscopy with edax (FESEM-EDAX) X-ray diffraction spectroscopy (XRD) Raman analyses followed by kinetic study. The results proved that the newly developed graphene oxide carried ruthenium-silver nanoparticles catalysts can be more efficient to reductive, oxidative and of environmentally important organic pollutant. It also has good biological activity.
\end{abstract}

Keywords: Graphene oxide, Silver, Ruthenium, nanoparticles.

\section{INTRODUCTION}

Nanotechnology is rapidly growing by producing nanoproducts and nanoparticles that can have novel and size-related physico-chemical properties differing significantly from larger matter [1]. The novel properties of nanoparticles have been exploited in a wide range of potential applications in medicine, cosmetics, renewable energies, environmental remediation and biomedical devices [2-4]. Among them, silver nanoparticles (AgNPs or nanosilver) have attracted increasing interest due to their unique physical, chemical and biological properties compared to their macro-scaled counterparts [5]. Silver nanoparticles have distinctive physico-chemical properties, including a high electrical and thermal conductivity, surface-enhanced Raman scattering, chemical stability, catalytic activity and nonlinear optical behavior [6]. These properties make them of potential value in inks, microelectronics, and medical imaging [7]. The silver nanoparticles exhibit broad spectrum bactericidal and fungicidal activity [8] that has made them extremely popular in a diverse range of consumer products, including plastics, soaps, pastes, food and textiles, increasing their market value [9-11]. To date, nanosilver technologies have appeared in a variety of manufacturing processes and end products. Nanosilver can be used in a liquid form, such as a colloid (coating and spray) or contained within a shampoo (liquid) and can also appear embedded in a solid such as a polymer master batch or be suspended in a bar of soap (solid) [9-11].
Silver nanoparticles have size between $1 \mathrm{~nm}$ and $100 \mathrm{~nm}$. While frequently described as being 'silver' some are composed of a large percentage of silver oxide due to their large ratio of surface-to-bulk silver atoms. Additional applications include molecular diagnostics and photonic devices, which take advantage of the novel optical properties of these nanomaterials. An increasingly common application is the use of silver nanoparticles for antimicrobial coatings, and many textiles, keyboards, wound dressings, and biomedical devices now contain silver nanoparticles that continuously release a low level of silver ions to provide protection against bacteria thus the noble silver nanoparticles are drawing increasing attention for potential prevention of bacterial/fungal and viral infections due to their well-documented antimicrobial and disinfectant properties. The generation of stable and efficient silver nanoparticles forms offers an advanced perspective in the field of environmental hygiene and sterilization. Next, toxicology considerations of silver nanoparticles to humans and ecology, some current applications of silver nanoparticles for environmental treatments are described. Future prospects of silver nanoparticles for treatment and prevention of currently emerging infections.

Silver nanoparticles are one of the most commonly utilized nanomaterials due to their antimicrobial properties, high electrical conductivity and optical properties. Silver nanopaticles are widely incorporated into wound dressings and are used as an antiseptic and disinfectant in medical applications and in consumer goods. Silver nanoparticles have a high surface area 
per unit mass and release a continuous level of silver ions into their environment. The silver ions are bioactive and have broad spectrum antimicrobial properties against a wide range of bacteria. By controlling the size, shape, surface and agglomeration state of the nanoparticles, specific silver ion release profiles can be developed for a given application. Each batch of nanoparticles is extensively characterized using transmission electron microscopy (TEM) images, dynamic light scattering (for particle size analysis), zeta potential measurements, and $\mathrm{UV} /$ visible spectral analysis to ensure consistent materials in every order.

Currently, many methods have been reported for the synthesis of silver nanoparticles by using chemical, physical, photochemical and biological routes. Chemical methods provide an easy way to synthesize silver nanoparticles in solution. Monodisperse samples of silver nanocubes were synthesized in large quantities by reducing silver nitrate with ethylene glycol in the presence of poly(vinyl pyrrolidone) (PVP) [12], the so-called polyol process. Spherical silver nanoparticles with a controllable size and high monodispersity were synthesized by using the polyol process and a modified precursor injection technique [13]. Nearly monodisperse silver nanoparticles have been prepared in a simple oleylamine-liquid paraffin system [14]. Generally, the chemical synthesis process of silver nanoparticles in solution usually employs the following three main components: (i) metal precursors, (ii) reducing agents and (iii) stabilizing/ capping agents. The formation of colloidal solutions from the reduction of silver salts involves two stages of nucleation and subsequent growth. The initial nucleation and the subsequent growth of initial nuclei can be controlled by adjusting the reaction parameters such as reaction temperature, $\mathrm{pH}$, precursors, reduction agents (i.e. $\mathrm{NaBH}_{4}$, ethylene glycol, glucose) and stabilizing agents (i.e. PVA, PVP, sodium oleate) [15-17]. Therefore, various methods of synthesis of silver nanoparticles based on the physical approach have been developed. A thermaldecomposition method was developed to synthesize silver nanoparticles in powder form [18]. The physical synthesis process of silver nanoparticles usually utilizes the physical energies (thermal, AC power, arc discharge) to produce silver nanoparticles with nearly narrow size distribution. The nanoparticles are formed by the direct photoreduction of a metal source or reduction of metal ions using photochemically generated intermediates, such as excited molecules and radicals, which is often called photosensitization in the synthesis of nanoparticles $[19,20]$. The main advantages of the photochemical synthesis are: (i) it provides the advantageous properties of the photo-induced processing, that is, clean process, high spatial resolution and convenience of use, (ii) the controllable in situ generation of reducing agents; the formation of nanoparticles can be triggered by the photo irradiation and (iii) it has great versatility; the photochemical synthesis enables one to fabricate the nanoparticles in various mediums including emulsion, surfactant micelles, polymer films, glasses, cells, etc. [20]. Silver nanoparticles have been demonstrated as an effective biocide against a broad-spectrum bacteria including both Gram-negative and Gram-positive bacteria [21], in which there are many highly pathogenic bacterial strains. Fungi are increasingly recognized as major pathogens in critically ill patients, especially noso- comial fungal infections [22]. Although the antibacterial activities of silver nanoparticles are well-known, the antifungal activities of this material have not yet been studied adequately.

\section{EXPERIMENTAL}

Graphite powder, potassium tetrachloropalladatate, silver nitrate, ruthenium trichloride hydrate, potassium dichromate, Rhodamine-B and malachite green, formic acid and sodium borohydride are procured from SRL while Eosin-Y is procured from Alfa aesar. Double distilled water was used throughout the experiment.

Graphine oxide (GO) was prepared by the using Hummer method and exfoliated into graphene oxide by sonication in water. These graphene oxide supported mono and bimetallic nanoparticles catalyst were prepared by chemical reduction method. The first catalyst viz., Ru-Ag bimetallic nanoparticles was prepared by taking in a $100 \mathrm{~mL}$ round bottom flask, typically, $0.06 \mathrm{~mm}$ of ruthenium trichloride hydrate was added. The above mixture is added to graphene oxide (5 mg and 30 $\mathrm{mL}$ water for $30 \mathrm{~min}$ ) and the reaction was stirred for further $2 \mathrm{~h}$ at $120^{\circ} \mathrm{C}$. Then the reaction mixture was added to $0.1 \mathrm{M}$ sodium borohydride and the solution was cooled and centrifuged at $2500 \mathrm{rpm}$. The water and ethanol were used for further purification. The collected compound was moist at $70{ }^{\circ} \mathrm{C}$ in vacuum oven.

Similarly by treating the identical amount of the substances and innovative procedure the bimetallic and monometallic nanoparticles catalysts viz., $\mathrm{Ru} / \mathrm{Ag}, \mathrm{Ru}$ and $\mathrm{Ag}$ nanoparticles were also prepared. The metal precursors for $\mathrm{Ru} / \mathrm{Ag}, \mathrm{Ru}$ and AgNPs were $\mathrm{AgNO}_{3}$ and $\mathrm{RuCl}_{3} \cdot \mathrm{H}_{2} \mathrm{O}$ solution. The reduction of $\mathrm{Ag}^{+} / \mathrm{Ru}^{3+}, \mathrm{Ru} / \mathrm{Ag}, \mathrm{Ru}$ and $\mathrm{AgNPs}$ was noticed through the changing of the colour. The resulting two different bimetallic nanoparticles catalysts were characterized with SEM, FESEMEDAX, HRTEM, Raman, XRD and XPS analysis.

The catalytic activities of as-synthesized graphene oxidesupported mono and bimetallic nanoparticles catalysts have been explored for the reduction of $\mathrm{Cr}(\mathrm{VI})$ in aqueous solution using formic acid. The bimetallic catalysts convert $\mathrm{Cr}(\mathrm{VI})$ to $\mathrm{Cr}$ (III) at room temperature $\left(25^{\circ} \mathrm{C}\right)$, in the model reaction performed keeping under identical pseudo-first order experimental condition. The reaction was checked in a standard quartz cuvette with $1 \mathrm{~cm}$ path length to which $2.5 \mathrm{~mL}$ water, $0.25 \mathrm{~mL} \mathrm{~K}_{2} \mathrm{Cr}_{2} \mathrm{O}_{7}$, $1 \mathrm{~mL}$ of formic acid and $5 \mathrm{mg}$ of GO-Ru-AgNPs was added. After mixing the respective solution the corresponding cuvette was settled in a UV-visible spectrometer prolonging the temperature at $27^{\circ} \mathrm{C}$. The reaction was studied from $200-700 \mathrm{~nm}$, the reductive conversion of $\mathrm{Cr}(\mathrm{VI})$ to $\mathrm{Cr}(\mathrm{III})$ was observed at $348 \mathrm{~nm}$ which decreased the absorbance as the conversion proceeded. The decreasing trend of the characteristic peak was recorded at systematic meanwhile of time $(5 \mathrm{~min})$ and the same has been used for the estimation of pseudo first order rate constant. The pseudo first rate constant was calculated using the formula:

$$
\left.\mathrm{K}_{\mathrm{obs}}=\ln \left[\mathrm{A}_{\infty}-\mathrm{A}_{\mathrm{o}}\right) /\left(\mathrm{A}_{\infty}-\mathrm{A}_{\mathrm{t}}\right)\right] / \mathrm{t}
$$

where, $\mathrm{A}_{\infty}=$ absorbance at infinity time, $\mathrm{A}_{\mathrm{o}}=$ initial absorbance, $\mathrm{A}_{\mathrm{t}}=$ absorbance at different time $\mathrm{t}$.

The comparative catalytic reductive change of $\mathrm{Cr}(\mathrm{VI})$ to $\mathrm{Cr}$ (III) for another one bimetallic and three monometallic 

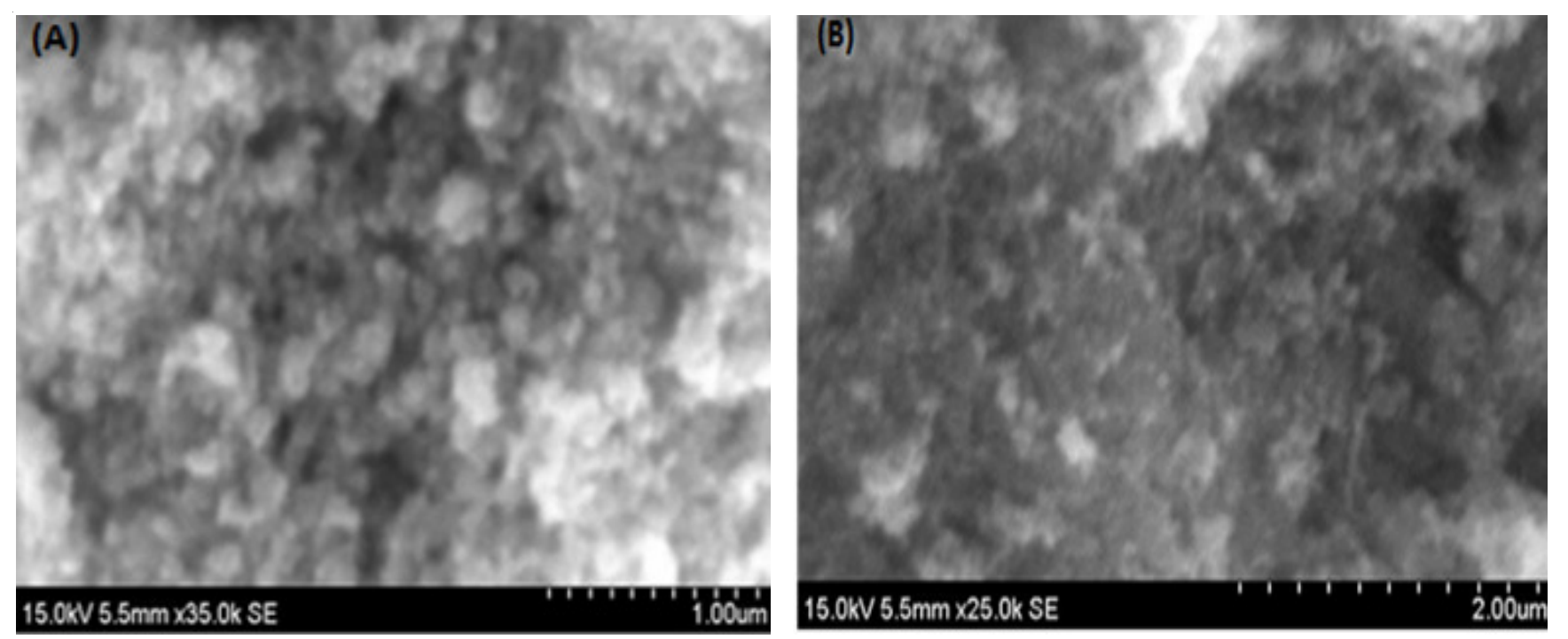

Fig. 1. (A) SEM images of GO-Ag and (B) GO-Ru nanoparticles

nanoparticles catalysts were followed under same conditions. The observed plot of conversion vs. time reveals that GO-Ru/ AgNPs catalyst is found to be superior catalyst as compare to other bimetallic and monometallic nanoparticles.

Antibacterial activity: The antibacterial activity of GO supported mono and bimetallic nanoparticles catalysts was studied against four bacterial separated such as Staphylococcus aureus, Escherichia coli, Salmonella typhi and Bacillus subtilis using agar effectively dispersal method. Nutrient agar plates were injected with $100 \mu \mathrm{L}$ of equalized culture $\left(1.5 \times 10^{8} \mathrm{CFU} /\right.$ $\mathrm{mL}$ ) of each bacterium (in triplicates) and devolped with infertile swabs. Wells of $6 \mathrm{~mm}$ size are produced in the agar plates involving the bacterial lawn. The synthesized GO supported $\mathrm{Ru}-\mathrm{Ag}$ bimetallic nanoparticles 50, 100 and 150 $\mu \mathrm{g}$ volume were poured into the wells made in the bacterial culture plates. The plates thus developed were left at room temperature for $10 \mathrm{~min}$ for allowing the diffusion of the extract into the agar bacterial lawn. After incubation for $24 \mathrm{~h}$ at $37^{\circ} \mathrm{C}$, the plates were noticed. The region of difference was measured and showed in millimeters.

\section{RESULTS AND DISCUSSION}

The simple approaches for the fabrication of GO-supported Go-Ag, GO-Ru as well as GO-Ag-Ru nanoparticles were synthesized by co-reduction method using $\mathrm{NaBH}_{4}$ in aqueous medium. The catalyst of graphene oxide supported GO-Ag-Ru nanoparticles was synthesized. The obtained products viz., GO$\mathrm{Ag}, \mathrm{GO}-\mathrm{Ru}$ and GO-Ag-Ru nanoparticles were characterized. The catalytic efficiency of the newly developed nanoparticles was measured for the reduction of organic dyes as a model reaction. The reduction reaction was observed by using UVvisible techniques and the reusability of the superior catalyst was examined up to 3 cycles for the same reduction reaction.

SEM: The surface morphology of GO-Ag and Go-Ru nanoparticles catalysts was performed by SEM analysis and the observed results are compared with corresponding polymer control that is the SEM image was found to be smooth in surface without any heterogeneity. In contrast, $\mathrm{Ag}$ and $\mathrm{Ru}$ nanoparticles obtained from Fig. 1A and $1 \mathrm{~B}$ revealed that irrespective of the images, there is an evenly distributed white dot have appeared on the surface of GO-Ag and GO-Ru nanoparticles. This must be a contribution of formation of evenly distributed nanoparticles on the surface of the spherical shape. Based on the results monometallic nanoparticles are well supported by graphene oxide.

FESEM: The surface morphology of graphene oxide supported GO-Ag-Ru alloy nanoparticles were investigated by using FESEM analysis. Fig. 2 shows the surface morphology of graphene oxide supported Ru-Ag nanoparticles. It clearly indicates that the spherical shape of Ru-Ag nanoparticles was supported by graphene oxide. Based on the above results, GO$\mathrm{Ag}-\mathrm{Ru}$ nanoparticles is well supported by graphene oxide.

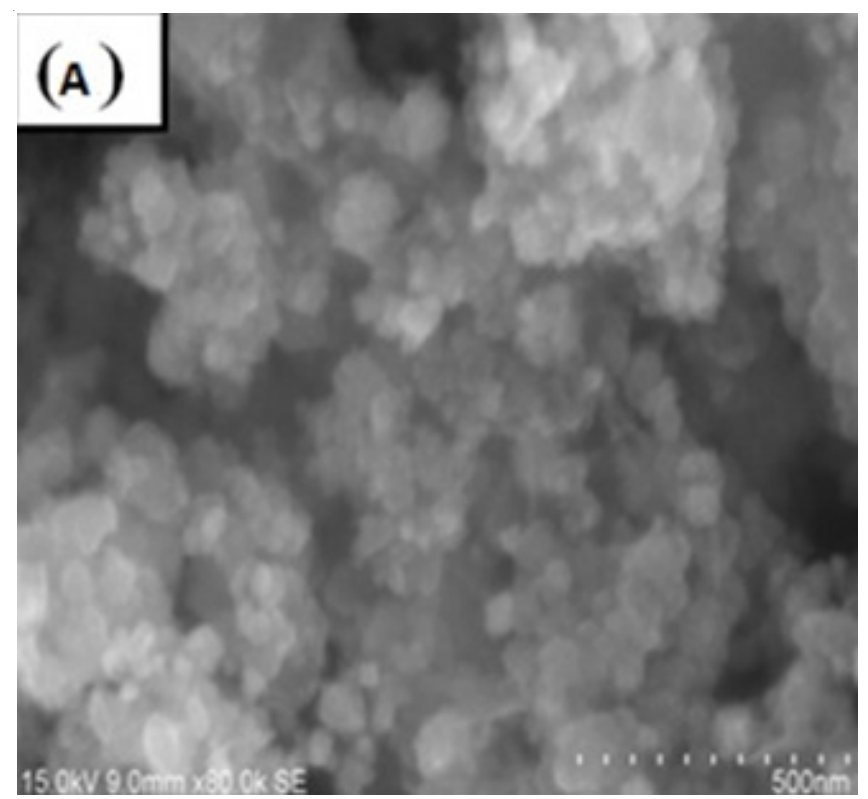

Fig. 2. FESEM images of GO-Ru-Ag bimetallic nanoparticles

EDAX: The weight percentage of $\mathrm{Ag}, \mathrm{Ru}$ and $\mathrm{Ru}-\mathrm{Ag}$ alloy nanoparticles were determined by EDAX analysis (Fig. 3A-C). From the EDAX measurement, the monometallic graphene oxide supported GO-Ag nanoparticles contain $35.40 \mathrm{wt} \%$ of $\mathrm{Ag}$ and GO-Ru nanoparticles contain $34.50 \mathrm{wt} \%$ of ruthenium. 

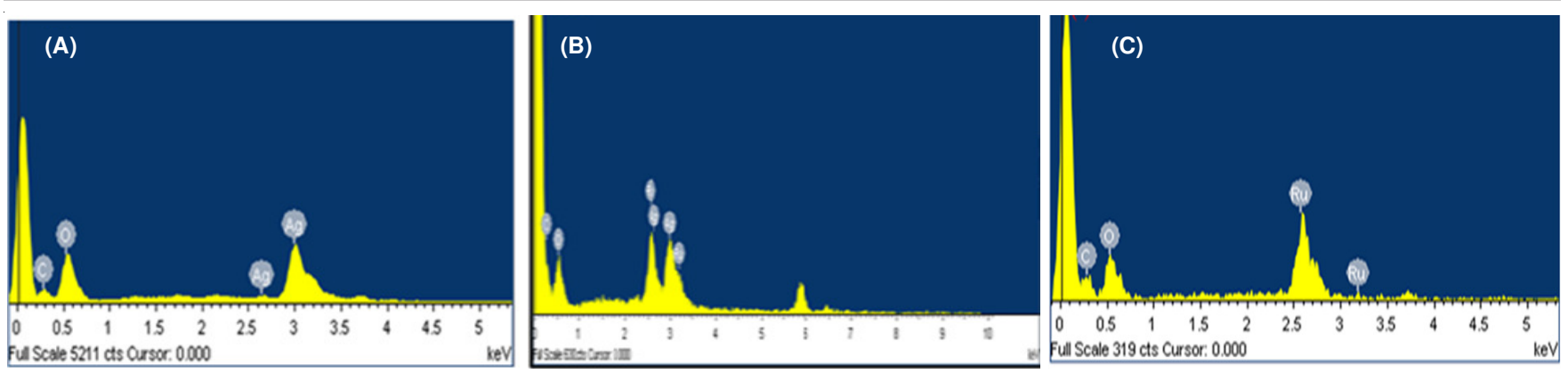

Fig. 3. (A) EDAX spectra of GO-Ag monometallic nano-particles (B) GO-Ru-Ag bimetallic nanoparticles and (C) GO-Ru monometallic nanoparticles

Graphene oxide supported bimetallic Ru-Ag alloy nanoparticles and 30.9 wt \% of silver nanoparticles, respectively.

Raman spectral analysis: Raman spectra of graphene oxide the $\mathrm{D}$ band around $1354 \mathrm{~cm}^{-1}$ and $\mathrm{G}$ band around 1549 $\mathrm{cm}^{-1}$ confirm the formation of graphene oxide (Fig. 4). The Raman spectra of graphene oxide supported the formation of mono GO-Ag, GO-Ru nanoparticles and bimetallic GO-Ru$\mathrm{Ag}$ alloy nanoparticles. The $\mathrm{D}$ band around at $1360 \mathrm{~cm}^{-1}$ and $\mathrm{G}$ band around at $1608 \mathrm{~cm}^{-1}$ were observed for the all GO supported mono nanoparticles as well as bimetallic alloy nanoparticles (Fig. 5A-C). It suggested that graphene oxide are well supported for the deposition of mono nanoparticles and bimetallic alloy nanoparticles.



Fig. 4. Raman spectra of graphene oxide
HRTEM: The particle size and shape of graphene oxide supported GO-Ru-Ag alloy nanoparticles were investigated by using HRTEM analysis. Fig. 6 shows the HRTEM image of graphene oxide supported Ru-Ag nanoparticles, the particles are spherical shapes with around 10-15 nm size. Based on the above results, the prepared bimetallic alloy nanoparticles is uniformly distributed on the graphene oxide surface. It should be noted that almost no nanoparticles can be observed outside of graphene oxide sheets which indicates that graphene oxide serves here as a template for nanoparticles formation.

XRD: The GO-Ru-Ag alloy nanoparticles were obtained after centrifugation and the dried samples were analyzed by powder XRD to determine their crystalline nature and particles size with $2 \theta$ values between 20 to $80{ }^{\circ} \mathrm{C}$. Fig. 7 showed the characteristic peaks for crystalline mono silver nanoparticles and bimetallic $\mathrm{Ru}-\mathrm{Ag}$ nanoparticles. The characteristic $2 \theta$ values at $20.01^{\circ}, 36.02^{\circ}, 38.1^{\circ}, 44.2^{\circ}, 64.4^{\circ}, 77.3^{\circ}$ and $81.5^{\circ}$ for $\mathrm{Ru}-\mathrm{Ag}$ nanoparticles are corresponds to $101,112,111$, 200, 220, 311 and 222 planes, respectively.

These peaks confirm the formation of AgNPs, which are in good agreement with the JCPDS files no 87- 597 and JCPDS files no1-1253 and 81-597of Ru-AgNPs. Moreover, there is no additional impurity peaks were observed, which indicates only crystalline mono silver and bimetallic nanoparticles are present. Based on the above results, the mono silver as well as bimetallic $\mathrm{Ru}-\mathrm{Ag}$ alloy nanoparticles are well supported by graphene oxide.

Comparative catalytic effect of GO-ruthenium and GO-ruthenium-silver nanoparticles catalysts for the reduction of organic dyes: The relatively catalytic effect of GO-Ru,GO$\mathrm{Ag}$ and GO-Ru-Ag nanoparticles catalysts was studied using
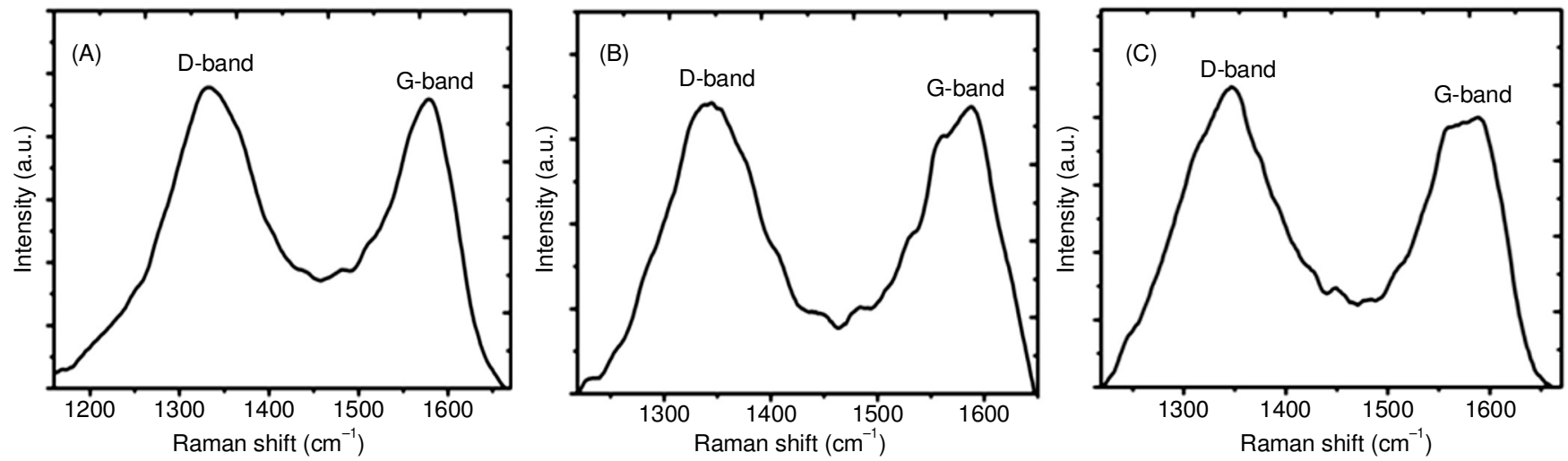

Fig. 5. Raman spectra of (A) GO-Ag nanoparticles (B) GO-Ru nanoparticles (C) GO-Ru-Ag bimetallic nanoparticles 

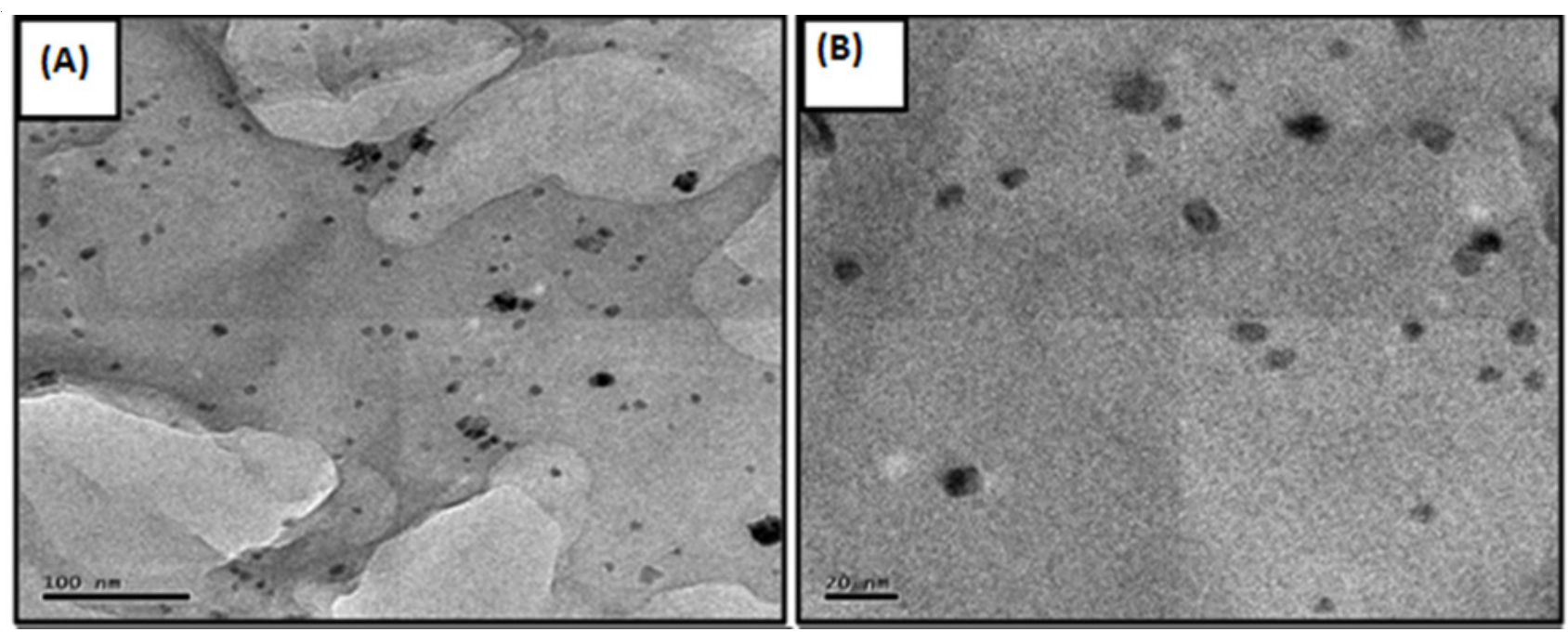

Fig. 6. HRTEM images of (A-B) GO-Ru-Ag bimetallic nanoparticles
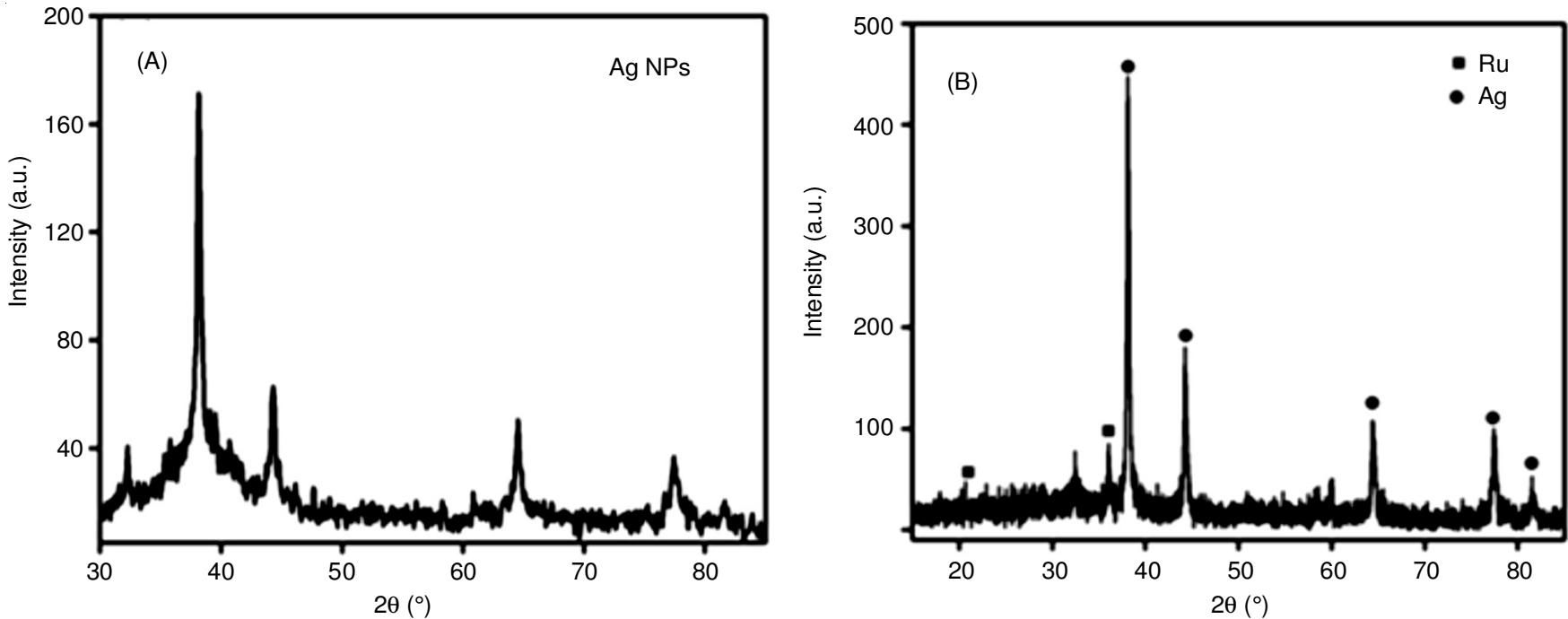

Fig. 7. XRD spectra of (a) GO-Ag nanoparticles (b) GO-Ru-Ag nanoparticles

reduction of organic dyes as a model reaction under pseudo first order identical condition. Figs. 8 and 9 show representative successive UV-visible spectra of the reduction of rhodamine $\mathrm{B}$ and malachite green in the presence of $\mathrm{NaBH}_{4}$.

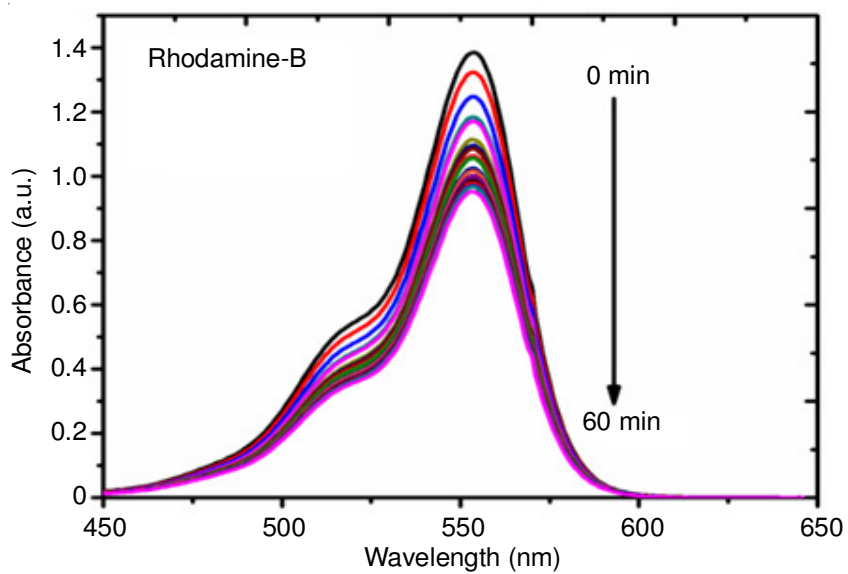

Fig. 8. UV-visible spectrum for the reduction of rhodamine-B using $\mathrm{NaBH}_{4}$ (control)



Fig. 9. UV-visible spectrum for the reduction of malachite green using $\mathrm{NaBH}_{4}$ (control)

Without catalysts there is slightly decrease of rhodamine$\mathrm{B}$ and Malachite green dyes in Figs. 8 and 10. Additionally Figs. 9 and 11 show in the presence of catalysts the peak gradually decreased at $544 \mathrm{~nm}$ and $617 \mathrm{~nm}$. 


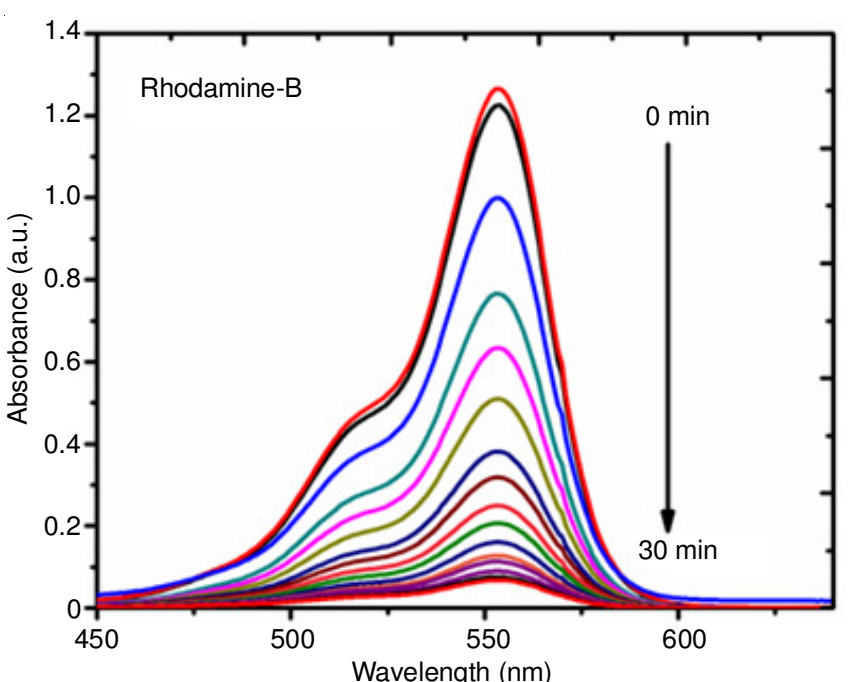

Fig. 10. UV-visible spectrum for the reduction of rhodamine-B using GO$\mathrm{Ru}-\mathrm{Ag}$ bimetallic nanoparticles catalysts

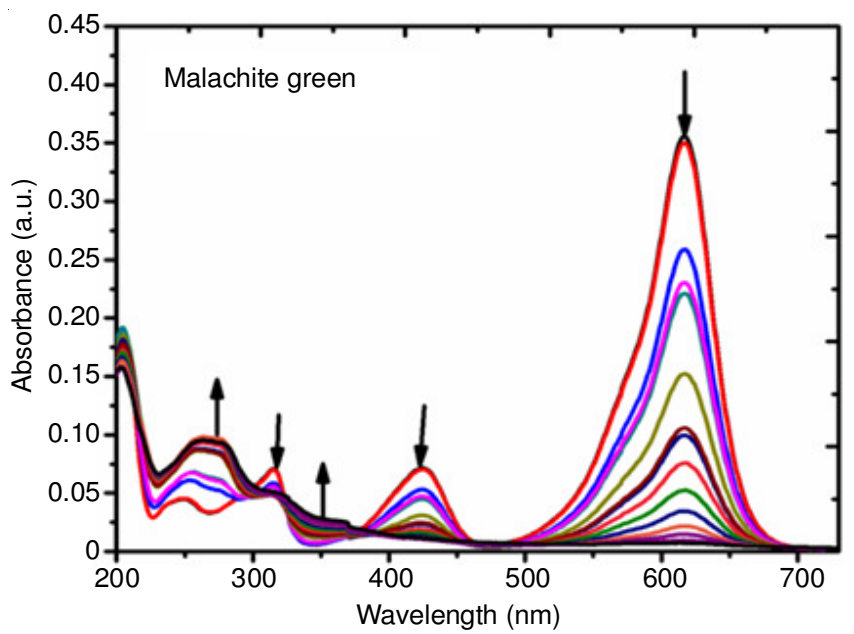

Fig. 11. UV-visible spectrum for the reduction of malachite green using GO$\mathrm{Ru}-\mathrm{Ag}$ bimetallic nanoparticles catalysts

The comparative catalytic reduction of pseudo first order rate constants for the reduction of rhodamine-B and malachite green are given the Tables 1 and 2 . Comparative catalytic activity for rhodamine-B reduction.

TABLE-1

[Rh-B]: $1.0 \mathrm{Mm}$; [ $\left.\mathrm{NaBH}_{4}\right]: 100 \mathrm{Mm}$; [Catalyst]: $5 \mathrm{mg}$; Temp: $27^{\circ} \mathrm{C}$

\begin{tabular}{ccc}
\hline S. No. & Name of the catalyst & $\mathrm{K}_{\mathrm{obs}} \times 10^{-3} \mathrm{~s}^{-1}$ \\
\hline 1 & GO-Ru NPs & 1.47 \\
2 & GO-Ag NPs & 1.67 \\
3 & GO-Ru-Ag NPs & 1.77 \\
\hline
\end{tabular}

\begin{tabular}{|c|c|c|}
\hline \multicolumn{3}{|c|}{$\begin{array}{c}\text { TABLE-2 } \\
\text { COMPARATIVE CATALYTIC ACTIVITY FOR } \\
\text { MALACHITE GREEN REDUCTION }\end{array}$} \\
\hline S. No. & Catalyst & $\mathrm{K}_{\mathrm{obs}} \times 10^{-3}\left(\mathrm{~s}^{-1}\right)$ \\
\hline 1 & GO-Ru NPs & 0.4934 \\
\hline 2 & GO-Ag NPs & 0.8126 \\
\hline 3 & GO-Ru-Ag NPs & 1.3850 \\
\hline
\end{tabular}

From the $\mathrm{K}_{\mathrm{obs}}$ results, the order of the rate constant is $\mathrm{Ag}$, $\mathrm{Ru}$ and $\mathrm{Ru}-\mathrm{Ag}$ NPs. The observed rate constant for the reduction of rhodamine-B and malachite green using $\mathrm{Ru}-\mathrm{Ag}$
NPs $\mathrm{K}_{\mathrm{obs}}=1.77 \times 10^{-3} \mathrm{~s}^{-1}$ and $1.3850 \times 10^{-3} \mathrm{~s}^{-1}$ was found to be higher than other GO-Ru-Ag nanoparticles catalyst. The reason for increased $\mathrm{K}_{\mathrm{obs}}$ noticed in Ru-Ag NPs may be alloted to the successive reactor that is, from the HRTEM studies, it is understood that size distribution of the Ru-Ag NPs catalyst was found to be relatively smaller $10 \mathrm{~nm}$ than another catalyst viz., GO-Ru-Ag NPs $10 \mathrm{~nm}$, which in turn more surface area (or) surface-volume-ratio in GO-Ru-Ag NPs catalyst was found to be superior in catalyzing the organic dyes reduction than with the GO-Ru-Ag NPs catalyst.

Catalytic effect of mono and bimetallic nanoparticles catalysts for reductive conversion of $\mathbf{C r}$ (VI) to $\mathbf{C r}$ (III): The comparative catalytic effect of mono and bimetallic nanoparticles catalysts such as Ag NPs and Ru NPs, Ru-Ag NPs for was studied using reduction of heavy metal ion and organic dyes as a model reaction under pseudo first order identical condition.

Fig. 12 presents the UV-visible spectra of the reaction solutions for the reductive conversion of $\mathrm{Cr}$ (VI) to $\mathrm{Cr}$ (III) over various mono metallic and bimetallic nano catalysts along with the plot of $\mathrm{At} / \mathrm{A}_{0}$ versus reaction time, respectively. $\mathrm{A}_{\mathrm{t}}$ represents absorbance of the $348 \mathrm{~nm}$ peaks at different time intervals during the catalytic reductions whereas $\mathrm{A}_{0}$ is the initial absorbance of the $348 \mathrm{~nm}$ peak before addition of the catalysts. In the preliminary investigation, there was no significant conversion of $\mathrm{Cr}(\mathrm{VI})$ as evidenced from the UV-visible spectra of the reaction solutions only in the presence of the reducing agent, i.e. $\mathrm{HCOOH}$ or the catalyst (Fig. 12). After the addition of both the reducing agent as well as the catalyst, the intensity of the characteristic absorption peak at $348 \mathrm{~nm}$ decreased with time. A change in the color of the reaction solution was also observed from yellow to colorless with increasing reaction time, signifying the reduction of $\mathrm{Cr}(\mathrm{VI})$. The presence of $\mathrm{Cr}$ (III) was further established by excess addition of $\mathrm{NaOH}$ solution, the colourless solution turns green in color which is characteristic of the presence of $\mathrm{Cr}$ (III) due to the formation of hydroxochromate(III). As mentioned earlier, aqueous solution of $\mathrm{Cr}(\mathrm{VI})$ only in the presence of $\mathrm{HCOOH}$ did not show a notable decrease in the absorption intensity of $348 \mathrm{~nm}$ peak within 60 min (Fig. 12).

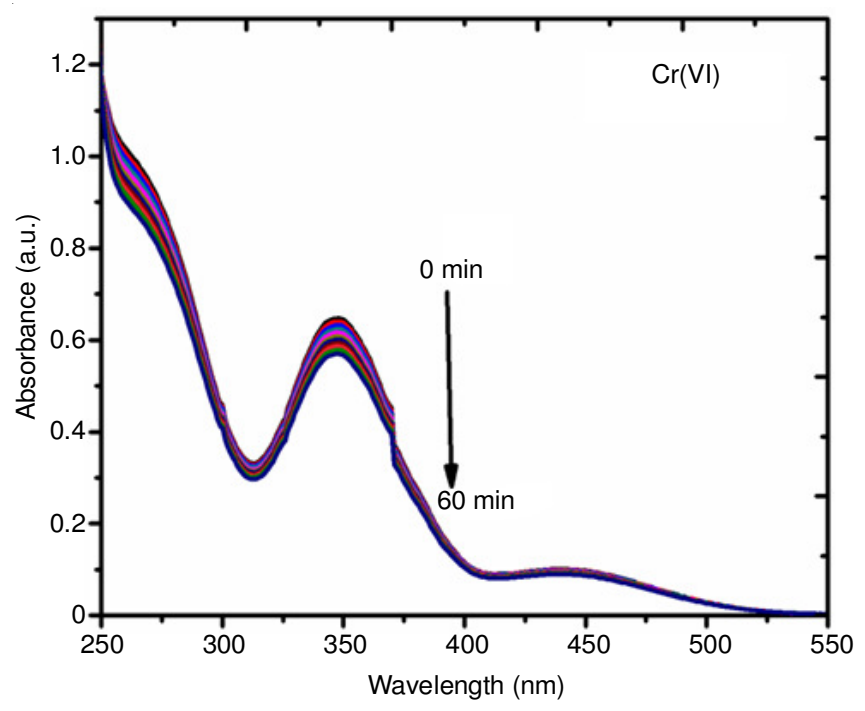

Fig. 12. UV-visible spectrum for the reduction of $\mathrm{Cr}(\mathrm{VI})$ to $\mathrm{Cr}(\mathrm{III})$ using formic acid (control) 
This suggests that the reductive conversion of $\mathrm{Cr}(\mathrm{VI})$ does not proceed without the presence of a catalyst. Similar behaviour observed when only the catalyst was used without $\mathrm{HCOOH}$, which signifies that the simultaneous presences of $\mathrm{HCOOH}$ as well as the catalyst in the reaction medium are prerequisite. However, it is noticed that monometallic nanoparticles exhibit much inferior activities for the reductive conversion of $\mathrm{Cr}(\mathrm{VI})$ to $\mathrm{Cr}$ (III) Within the reaction time investigated (i.e. $35 \mathrm{~min}$ ), monometallic nanoparticles demonstrated only 70.5, 75 and $80 \%$, conversion of $\mathrm{Cr}(\mathrm{VI})$, respectively and $\mathrm{Ru}-\mathrm{Ag}$ nanoparticles shows $85 \%$ conversion of $\mathrm{Cr}(\mathrm{VI})$.

Catalytic effect of mono and bimetallic nanoparticles catalysts for reduction of eosin-Y: The comparative catalytic effect of mono and bimetallic nanoparticles catalysts such as $\mathrm{Ag}$, and Ru NPs for monometallic nanoparticles Ru-Ag NPs for bimetallic nanoparticles was studied using reduction of Eosin y as a model reaction under pseudo first order identical condition. Fig. 13 shows representative successive UV-visible spectra of the reduction of eosin- $\mathrm{Y}$ the presence of $\mathrm{NaBH}_{4}$. Fig. 13 shows in the presence of catalysts the peak gradually decreased at $548 \mathrm{~nm}$.



Fig. 13. UV-visible spectrum for the reduction of eosin-Y using $\mathrm{NaBH}_{4}$ (control)

Antibacterial activity: Further the graphene oxide supported Ag NPs and Ru NPs as well as Ru-Ag nanoparticles catalyst by using antibacterial activity. Two strains including Gram-negative E. coli and Salmonella typhimurium and Grampositive Bacillus subtilis and Staphylococcus aureus were selected for antibacterial tests because they are usually associated with the medical-associated infections. The comparative antibacterial property of GO-Ru-Ag, GO-Ag and GO-Ru nanoparticles was investigated by calculating antibacterial ratios based on the numbers of bacteria colonies incubated with different dosages of GO-supported mono and bimetallic nanoparticles at $37{ }^{\circ} \mathrm{C}$ after a contact time of $1 \mathrm{~h}$.

It was found that the antibacterial ratio increased mono metal nanoparticles to bimetallic nanoparticles with compared increasing GO-Ru-Ag nanoparticles dosages. Anti-E. coli ratio of $110 \mu \mathrm{g}$ dosage of GO-Ru-Ag nanoparticles reached 98.36 $\%$, respectively. Antibacterial ratios were $100 \%$ with more than $100 \mu \mathrm{L}$ dosage. Therefore, antibacterial behavior of graphene oxide-supported mono and bimetallic nanoparticles displayed a dose-dependent manner. The comparative antibacterial activity increases from mono to bimetallic nanoparticles are given in Tables 3-5.

\begin{tabular}{lccccc}
\multicolumn{5}{c}{ TABLE-3 } \\
ANTIBACTERIAL POTENTIAL OF GO-Ru-Ag \\
BIMETALLIC NANOPARTICLES CATALYST \\
\hline \multirow{2}{*}{$\begin{array}{c}\text { Human bacterial } \\
\text { pathogens }\end{array}$} & \multicolumn{5}{c}{ Zone of inhibition $(\mathrm{mm})$} \\
\cline { 2 - 6 } & \multicolumn{5}{c}{ Concentration $(\mu \mathrm{g} / \mathrm{mL})$} \\
\cline { 2 - 6 } & $\mathrm{a}$ & $\mathrm{b}$ & $\mathrm{c}$ & $\mathrm{d}$ & $\mathrm{e}$ \\
\hline Salmonella typhi & 0.5 & 2.5 & 4 & 9 & - \\
Bacillus subtilis & 2.5 & 3.5 & 5 & 7 & - \\
Staphylococcus aureus & - & 3.0 & 4 & 7 & - \\
Escherichia coli & &
\end{tabular}

TABLE-4

ANTIBACTERIAL POTENTIAL OF GO-Ag MONOMETALLIC NANOPARTICLES CATALYST

\begin{tabular}{lccccc}
\hline \multirow{2}{*}{$\begin{array}{c}\text { Human bacterial } \\
\text { pathogens }\end{array}$} & \multicolumn{5}{c}{ Zone of inhibition $(\mathrm{mm})$} \\
\cline { 2 - 6 } & $\mathrm{a}$ & $\mathrm{b}$ & $\mathrm{c}$ & $\mathrm{d}$ & $\mathrm{e}$ \\
\cline { 2 - 6 } & 2.0 & 3.0 & 4.0 & 8 & - \\
\hline Salmonella typhi & 0.2 & 1.5 & 2.5 & 9 & - \\
Bacillus subtilis & 1.0 & 2.0 & 2.7 & 7 & - \\
Staphylococcus aureus & - & 1.5 & 2.5 & 7 & - \\
Escherichia coli & & & & & \\
\hline
\end{tabular}

\begin{tabular}{|c|c|c|c|c|c|}
\hline \multicolumn{6}{|c|}{$\begin{array}{c}\text { TABLE-5 } \\
\text { ANTIBACTERIAL POTENTIAL OF GO-Ru } \\
\text { MONO METALLIC NANOPARTICLES CATALYST }\end{array}$} \\
\hline \multirow{3}{*}{$\begin{array}{l}\text { Human bacterial } \\
\text { pathogens }\end{array}$} & \multicolumn{5}{|c|}{ Zone of inhibition (mm) } \\
\hline & \multicolumn{5}{|c|}{ Concentration $(\mu \mathrm{g} / \mathrm{mL})$} \\
\hline & $\mathrm{a}$ & $\mathrm{b}$ & $\mathrm{c}$ & $\mathrm{d}$ & $\mathrm{e}$ \\
\hline Salmonella typhi & 1.0 & 1.5 & 2.0 & 8 & - \\
\hline Bacillus subtilis & 0.2 & 0.5 & 1.0 & 9 & - \\
\hline Staphylococcus aureus & 0.5 & 1.0 & 1.5 & 7 & - \\
\hline Escherichia coli & - & 0.5 & 1.7 & 7 & - \\
\hline
\end{tabular}

These results indicate that GO-supported bimetallic nanoparticles have excellent antibacterial activities compared to mono metallic nanoparticles against Gram-negative E. coli and Salmonella typhimurium and Gram-positive Bacillus subtilis and Staphylococcus aureus.

\section{Conclusion}

Graphene oxide supported two mono $\mathrm{Ru}, \mathrm{Ag}$ and one bimetallic Ru-Ag nanoparticles catalyst. The Ru-Ag and GO$\mathrm{Ru}-\mathrm{Ag}$ nanoparticles catalysts were characterized by scanning electron microscopy, high resolution transmission electron microscopy field emission scanning electron microscopy with EDAX (FESEM-EDAX) X-ray diffraction spectroscopy and Raman analyses. From the observed results it reveals that the newly developed graphene oxide supported bimetallic nanoparticles catalysts can be more efficient to reductive, oxidative and of environmentally important organic pollutant as well as good biologically active compound.

\section{REFERENCES}

1. Q.H. Tran, V.Q. Nguyen and A.T. Le, Adv. Nat. Sci.: Nanosci. Nanotechnol., 4, 1 (2013).

2. M. De, P.S. Ghosh and V.M. Rotello, Adv. Mater, 20, 4225 (2008); https://doi.org/10.1002/adma.200703183.

3. A.-H. Lu, E.L. Salabas and F. Schuth, Angew. Chem. Int. Ed. Engl., 46, 1222 (2007);

https://doi.org/10.1002/anie.200602866. 
4. R. Ghosh Chaudhuri and S. Paria, Chem. Rev., 112, 2373 (2012); https://doi.org/10.1021/cr100449n.

5. V.K. Sharma, R.A. Yngard and Y. Lin, Adv. Colloid Sur. Interf., 145, 63 (2009).

6. Y.A. Krutyakov, A.A. Kudrinskiy, A.Y. Olenin and G.V. Lisichkin, Russ. Chem. Rev., 77, 233 (2008); https://doi.org/10.1070/RC2008v077n03ABEH003751.

7. D.R. Monteiro, L.F. Gorup, A.S. Takamiya, A.C. Ruvollo-Filho, E.R Camargo and D.B. Barbosa, Antimicrob. Agents, 34, 103 (2009); https://doi.org/10.1016/j.ijantimicag.2009.01.017.

8. M. Ahamed, M.S. AlSalhi and M.K.J. Siddiqui, Clin. Chim. Acta, 411, 1841 (2010);

https://doi.org/10.1016/j.cca.2010.08.016.

9. J. García-Barrasa, J.M. López-de-Luzuriaga and M. Monge, Cent. Eur. J. Chem., 9, 7 (2011); https://doi.org/10.2478/s11532-010-0124-x.

10. J. Fabrega, S.N. Luoma, C.R. Tyler, T.S. Galloway and J.R. Lead, Environ. Int., 37, 517 (2011); https://doi.org/10.1016/j.envint.2010.10.012.

11. P. Dallas, V.K. Sharma and R. Zboril, Adv. Colloid Interface Sci., 166, 119 (2011);

https://doi.org/10.1016/j.cis.2011.05.008.

12. Y. Sun and Y. Xia, Science, 298, 2176 (2002); https://doi.org/10.1126/science.1077229.

13. D. Kim, S. Jeong and J. Moon, Nanotechnology, 17, 4019 (2006); https://doi.org/10.1088/0957-4484/17/16/004.
14. M. Chen, Y.G. Feng, X. Wang, T.C. Li, J.Y. Zhang and D.J. Qian, Langmuir, 23, 5296 (2007); https://doi.org/10.1021/la700553d.

15. S.F. Chen and H. Zhang, Adv. Nat. Sci.: Nanosci. Nanotechnol., 3, 035006 (2012); https://doi.org/10.1088/2043-6262/3/3/035006.

16. T.M.D. Dang, T.T.T. Le, E.F Blance and M.C. Dang, Adv. Nat. Sci.: Nanosci. Nanotechnol., 3, 035004 (2012); https://doi.org/10.1088/2043-6262/3/3/035004.

17. R.S. Patil, M.R. Kokate, C.L. Jambhale, S.M. Pawar, S.H. Han and S.S. Kolekar, Adv. Nat. Sci.: Nanosci. Nanotechnol., 3, 015013 (2012); https://doi.org/10.1088/2043-6262/3/1/015013.

18. D.K. Lee and Y.S. Kang, ETRI J., 26, 252 (2004); https://doi.org/10.4218/etrij.04.0103.0061.

19. A.J. Christy and M. Umadevi, Adv. Nat. Sci.: Nanosci. Nanotechnol., 3, 035013 (2013); https://doi.org/10.1088/2043-6262/3/3/035013.

20. M. Sakamoto, M. Fujistuka and T. Majima, J. Photochem. Photobiol. Chem., 10, 33 (2009); https://doi.org/10.1016/j.jphotochemrev.2008.11.002.

21. C. Marambio-Jones and E.M.V. Hoek, J. Nanopart. Res., 12, 1531 (2010); https://doi.org/10.1007/s11051-010-9900-y.

22. D.A. Enoch, H.A. Ludlam and N.M. Brown, J. Med. Microbiol., 55, 809 (2006); https://doi.org/10.1099/jmm.0.46548-0. 